Artigo original

Hegemonia - Revista Eletrônica de Relações Internacionais do Centro

Universitário Unieuro

ISSN: $1809-1261$

UNIEURO, Brasília, número 11, 2013, pp. 166-199

Recebido em: 28/11/2012

Revisado em: 20/12/2012

Aprovado em: 24/2/2013

\title{
A INFLUÊNCIA DA CONFERÊNCIA DE BEIJING NA FORMULAÇÃO DE POLÍGICAS PÚBLICAS PARA A PROMOÇÃO DO TRABALHO FEMININO NO MEIO RURAL BRASILEIRO
}

SANTOS, Lorayne de Oliveira ${ }^{1}$

\begin{abstract}
Resumo: Nas últimas décadas a questão das desigualdades entre os sexos se tornou um tema de discussão global. A divisão sexual do trabalho é um dos grandes motivos de disparidades econômicas entre os gêneros. Este trabalho tem como objetivo analisar de que forma algumas diretrizes da Conferência de Beijing (realizada em 1995) influenciam o governo brasileiro na implementação de políticas afirmativas para o emponderamento das mulheres rurais no mercado de trabalho, apontando limites e possibilidades de programas como o Pronaf. A implementação ainda alcança pequenos resultados, 0 que nos permite concluir que essas ações afirmativas se encontram em construção, pois existem muitas barreiras culturais no meio rural que impedem melhores resultados dessas políticas públicas.
\end{abstract}

Palavras-chave: Conferência de Beijing, divisão sexual do trabalho, gênero, Brasil, meio rural, relações internacionais, políticas públicas.

Abstract: In the recent decades the question of gender inequalities has become a topic of global discussion. The sexual division of labor is an enormous source of economic disparities among genders. The subject of this paper is to examine how some guidelines of the Beijing Conference (held in 1995) influence the Brazilian government to implement affirmative action policies for the empowerment of rural women in the labor market, pointing out limitations and possibilities of programs as the Pronaf. The implementation has achieved short results, allowing us to conclude that these affirmative actions are under construction, because there are many cultural barriers that prevent rural best results of these public policies. 


\section{Artigo original}

Hegemonia - Revista Eletrônica de Relações Internacionais do Centro

Universitário Unieuro

ISSN: $1809-1261$

UNIEURO, Brasília, número 11, 2013, pp. 166-199

Key-words: Beijing Conference, sexual division of labor, gender, Brazil, rural, international relations, public policies.

\section{Considerações Iniciais}

Ao longo da história da humanidade a mulher sempre esteve subjugada a vontade e aos papéis sociais impostos pelo domínio do homem. Através dos valores de cunho machista, os quais permeaiam os modos de agir e pensar de diversas civilizações, o gênero feminino foi vítima de violências no âmbito familiar, escolar, religioso, estatal e na divisão social do trabalho.

Entretanto, nas últimas décadas percebe-se inúmeras conquistas das mulheres frente à longa carga histórica de machismo que foi confeccionado. Agindo em prol de conquistas de direito sociais que trazem equidade em relação ao homem, elas têm cada vez mais se firmado em áreas antes vistas de domínio exclusivamente masculino.

Apesar de várias conquistas alcançadas no campo jurídico e político, a questão da desigualdade de gênero no mercado de trabalho se tonou uma problemática muito discutida e geradora de preocupações por parte da comunidade internacional e no âmbito interno dos Estados. Diante da constatação do fato que as mulheres tem salários baixos e ocupam empregos inferiores na divisão internacional do trabalho comparado aos postos ocupados pelos homens, esse tema alcançou um nível global de discussão e entendimento entre os governantes bastante expressivo.

Para agir frente a esta deficiência global era necessário promover mudanças para uma participação mais plena e igualitária da sociedade como um todo, rumo ao fortalecimento de Estados mais democráticos e que gerassem ações públicas para a promoção do trabalho feminino. Assim, surge a Conferência de Beijing, evento que foi um marco importante para as novas 


\section{Artigo original}

Hegemonia - Revista Eletrônica de Relações Internacionais do Centro Universitário Unieuro

ISSN: $1809-1261$

UNIEURO, Brasília, número 11, 2013, pp. 166-199

diretrizes de implementação de políticas públicas, sob a perspectiva de gênero, propostas aos diversos Estados signatários de sua Plataforma a implantarem tais metas de conquistas sociais em seu território nacional.

No Brasil, país cerceado de inúmeras disparidades econômicas e sociais, o gênero feminino ocupa funções ainda inferiores comparadas ao sexo oposto na divisão do trabalho. Tanto nos grandes centros urbanos como no meio rural as mulheres sofrem com a precarização de suas condições de emprego. Entretanto, é no meio rural aonde as disparidades na divisão sexual do trabalho são mais evidentes.

O Governo brasileiro é um dos Estados participantes da Conferência sucedida em território chinês, no qual tornou-se responsável publicamente pela melhoria das condições de trabalho para as mulheres de seu país. Diante do problema econômico-político vivido em chácaras e fazendas pelas mulheres brasileiras em contraste com a intenção governamental, lança-se a seguinte problematização: de que forma a Conferência de Beijing tem influenciado a administração pública brasileira no sentido de formular políticas que valorizem o trabalho feminino no meio rural do país?

O objetivo principal do estudo é analisar os limites e possibilidades de ações afirmativas de gênero implementadas pelo Brasil, de acordo com algumas diretrizes específicas no evento internacional aqui já citado anteriormente. O presente trabalho é uma pesquisa sobre os resultados da Conferência de Beijing e suas relações estabelecidas com a situação de gênero e trabalho vividas no Brasil. Visa-se analisar de que forma o governo brasileiro tem adotado ações da Plataforma de Beijing para realizar políticas públicas referentes à igualdade de gênero no mundo do trabalho brasileiro.

I. Breve histórico sobre as relações de trabalho entre homens e mulheres 


\section{Artigo original}

Hegemonia - Revista Eletrônica de Relações Internacionais do Centro Universitário Unieuro

ISSN: $1809-1261$

UNIEURO, Brasília, número 11, 2013, pp. 166-199

As relações de gênero e trabalho se dão, principalmente, a partir das desigualdades entre homens e mulheres em quesitos como: inserção no mercado de trabalho, diferenças salariais e condições de trabalho. A realidade da mulher no mundo do trabalho, desde as sociedades primitivas aos dias atuais, se reflete a partir da divisão de tarefas entre homens e mulheres tendo em vista as necessidades e possibilidades individuais de desempenho dos mesmos. Segundo o teórico Engels (apud GUTERRES, 2001), a primeira organização divisória do trabalho é a que se fez entre o homem e a mulher para a procriação dos filhos.

A não equidade entre gênero em diversas áreas sociais, sobretudo nas relações de trabalho, pode ser explicada por meio de uma ótica que define o gênero como parte de uma construção social e cultural pertencente às categorias oriundas na masculinidade e feminilidade. Assim, pode-se afirmar que existem especificidades consideradas 'naturais' que definem o masculino e o feminino. No entanto, não há nada naturalizado nas características atribuídas à homens e mulheres. Os gêneros não são categorias independentes, mas sim definidos a partir de uma relação de oposição de um ao outro; ser feminino é não ser masculino. No decorrer da história humana, houve uma constante prática da sociedade em assimilar nesse conceito grande valor ao que está associado à masculinidade e menor valor ao que é associado à feminilidade. Desse modo, alguns especialistas afirmam que:

Em primeiro lugar, gênero se refere às categorias social e culturalmente construídas na masculinidade e na feminilidade. A ênfase na construção natural destas categorias, destina-se a dizer que não há nada de natural, inerente ou biologicamente inevitável sobre os atributos, atividades e comportamentos que venham a ser definidos como masculinos ou femininos ${ }^{2}$ (ZALEWSKI, 1995:135).

2 Tradução livre do inglês, no qual o original consta da seguinte forma: First, gender refers to the socially and culturally constructed categories of masculinity and 


\section{Artigo original}

Hegemonia - Revista Eletrônica de Relações Internacionais do Centro

Universitário Unieuro

ISSN: $1809-1261$

UNIEURO, Brasília, número 11, 2013, pp. 166-199

Segundo a teoria feminista, as políticas e práticas estatais são informadas e construídas a partir de crenças sobre gênero, as quais tratando da exclusão de mulheres nas estruturas formais de poder e num ataque a cerda da autonomia reprodutiva e o direito ao trabalho. As mulheres ocupam as mais altas estatísticas de pobreza absoluta e esses dados são resultados, em parte, de crenças e construções das diferenças entre gêneros. As reivindicações radicais dessas diferenças são a única base para a legitimidade do Estado que age especificamente em prol do gênero masculino. Assim, tal ambiente constitui uma justificação explícita da exclusão das mulheres na participação no poder. Tradicionalmente elas são subvalorizadas em sua capacidade laboral, sempre comparadas aos homens que, por sua vez, fortalecem-se calcados em mitos que justificam a sua "superioridade" (GUTERRES apud SAFFIOTI, 2001).

O trabalho feminino subjugado, quer ele doméstico ou em outras áreas do trabalho produtivo, desvaloriza a própria mulher e miticamente justifica características propriamente femininas. Entretanto, não existem elementos concretos que possam explicar qualidades inerentes da mulher, tais como a delicadeza, a habilidade, a disciplina, etc.

O conceito de gênero construído por meio das diferenças biológicas e sexuais entre homens e mulheres está imerso num conjunto de oposições sobrecarregadas de determinações antropológicas e cosmológicas. Essa construção revela uma significação social que traduz as diferenças 'naturais' entre homens e mulheres. Afirmações essas que podem ser simplificadas na seguinte citação teórica: 
Artigo original

Hegemonia - Revista Eletrônica de Relações Internacionais do Centro

Universitário Unieuro

ISSN: $1809-1261$

UNIEURO, Brasília, número 11, 2013, pp. 166-199

Arbitrária em estado isolado, a divisão das coisas e das atividades (sexuais e outras) segundo a oposição entre o masculino e o feminino recebe sua necessidade objetiva e subjetiva de sua inserção em um sistema de oposições homólogas, alto/baixo, em cima/embaixo, na frente/atrás, direita/esquerda, reto/curvo (e falso), seco/úmido, duro/mole, temperado/insosso, claro/escuro, fora (público) /dentro (privado) etc., que, para alguns, correspondem a movimentos do corpo (alto/baixo//subir/descer, fora/dentro//sair/entrar). Semelhantes na diferença, tais oposições são suficientemente concordes para sustentarem mutuamente, no jogo e pelo jogo inesgotável de transferências práticas e metáforas; e também suficientemente divergentes para conferir, a cada uma, uma espécie de espessura semântica, nascida da sobredeterminação pelas harmonias, conotações e correspondências (BOURDIEU, 1999: 16).

As atribuições para denominar o masculino e o feminino inscrevem-se em um sistema de diferenças. Essa experiência apreende o mundo social e suas arbitrárias divisões, a começar pela diferenciação socialmente construída entre os sexos como naturais e evidentes. Nesse ambiente, ele adquire, assim, todo um reconhecimento de legitimação. A força da ordem masculina se evidencia no fato de que ela dispensa justificação, pois é entendida como neutra e dispensa discursos que visem legitimá-la, já que ela é naturalizável pela sociedade.

A ordem social, imbuída nas diferenças biológicas e sexuais entre homens e mulheres funciona em um contexto simbólico que tende a ratificar a dominação masculina sobre a qual se alicerça. Ela está claramente calcada na divisão social do trabalho, na qual as atividades são atribuídas aos dois sexos. Situações essas que as tornam bastante estritas como a "(...) estrutura do espaço, opondo o lugar de assembléia ou de mercado, reservados aos homens, e a casa, reservada às mulheres" (BOURDIEU, 1999: 18). Em uma estrutura rural, essa divisão de espaço é ainda mais visível, já que "(...) no interior 


\section{Artigo original}

Hegemonia - Revista Eletrônica de Relações Internacionais do Centro Universitário Unieuro

ISSN: $1809-1261$

UNIEURO, Brasília, número 11, 2013, pp. 166-199

desta, entre a parte masculina, com o salão, e a parte feminina, com o estábulo, a água, os vegetais; é a estrutura do tempo, a jornada, o ano agrário, ou o ciclo de vida, com momentos de ruptura, masculinos, e longos períodos de gestação, femininos" (BOURDIEU, 1999: 18).

Apesar das diversas características reservadas às mulheres e que as colocam em desvantagem ao sexo masculino no mercado de trabalho, elas conseguiram um maior espaço na sociedade. A partir da década de 80 percebe-se visivelmente o crescimento de postos de trabalho para mulheres, o que é fruto de uma redução na produção e da utilização de formas precárias de trabalho, tais como a terceirização. É possível notar que a inserção de mulheres no mercado de trabalho, ao longo da história, deu-se em períodos de maior precarização dessas relações. Acontecimentos esses que são momentos de crise em que a força laboral feminina era necessária e que se inseria de forma precarizada e desvalorizada no contexto mundial.

Outros motivos que explicam a maior participação feminina no mercado de trabalho é a queda na taxa de fecundidade, o crescente número de famílias chefiadas por mulheres e o nível de instrução maior do que a dos homens. No entanto, a divisão sexual no mundo trabalho é evidente quando se observa as diferenças salariais entre os dois gêneros que ocupam os mesmos postos. Estudos apontam que as mulheres só alcançam a igualdade salarial em relação aos homens quanto possuem uma melhor formação educacional. Fatores esses que fortalecem os preconceitos e as características que as deixam abaixo da força de trabalho que elas oferecem. Elas representam $51 \%$ da população mundial e desempenham dois terços de todo o trabalho. Porém, as mesmas possuem apenas cerca de $1 \%$ dos bens mundialmente produzidos e ganham $10 \%$ de toda renda mundial no globo segundo informações apuradas no Fundo Mundial para Mulheres (ANISTIA INTERNACIONAL, 21/06/2011).

A situação da mulher no mercado de trabalho, assim como outras questões de gênero, acabou se tornando temática na agenda da sociedade 


\section{Artigo original}

Hegemonia - Revista Eletrônica de Relações Internacionais do Centro Universitário Unieuro

ISSN: $1809-1261$

UNIEURO, Brasília, número 11, 2013, pp. 166-199

internacional como resultado da construção de um novo ordenamento internacional. Quer dizer, as novas pautas na agenda dos líderes governamentais redesenham, de certa forma, as suas relações e as consideram como parte de novos fenômenos globais, tais como as questões relacionadas ao meio ambiente, a fome, a miséria, as migrações em massa, a internacionalização das sociedades, a ampliação dos mercados, o impacto dos processos de integração regional e a economia política da globalização que emergem por meio do seu impacto nas políticas internas dos Estados nacionais (ALVES, 2001).

II. A Conferência de Beijing e a situação da mulher

Nas relações internacionais contemporâneas, as sociedades se preocupam cada vez mais com temas sociais. As últimas décadas do século $\mathrm{XX}$ foram caracterizadas por um processo de consolidação da nova linguagem dos direitos humanos, o que passou a contemplar também as preocupações com a cidadania feminina e as relações de gênero (NAÇõES UNIDAS, 21/06/2011).

Ademais, esses temas também se tornam relevantes para os Estados ao refletir a realização de conferências internacionais como a Cúpula Mundial sobre a Criança, a Rio 92, a Conferência de Viena de 1993 sobre Direitos Humanos, a Conferência do Cairo sobre População e Desenvolvimento, a Cúpula Mundial sobre o Desenvolvimento Social e os encontros de discussão de Copenhague e a Conferência de Beijing (a qual será tratada neste artigo). Essas conferências, as quais não possuem peso jurídico sobre os Estados, têm como objetivo a tentativa de melhoria da situação das minorias e uma nova visão das relações internacionais por meio da emergência de problemas que se tornaram globais. Considerações teóricas ampliadas pela reflexão a cerca do sentido dessas conferências: 
Artigo original

Hegemonia - Revista Eletrônica de Relações Internacionais do Centro

Universitário Unieuro

ISSN: $1809-1261$

UNIEURO, Brasília, número 11, 2013, pp. 166-199

(...) as conferências de 1990 têm, sem dúvida, caráter instrutivo. Elas evidenciaram o quão modificado se encontra o cenário em que se desenrolam atualmente tais relações, bastante diferente daquele em que os Estados eram os únicos atores de peso, a soberania nacional, matéria alegadamente intocável e as "políticas de poder" (ALVES, 2001: 39).

Foi em um cenário de grande discussão e da emergência das questões de gênero, que a Conferência de Beijing ${ }^{3}$ cria o marco regulatório que ampliam os direitos da mulher, o que está em conformidade com os direitos humanos fundamentais. Fatos esses que não somente os Estados deveriam observar, mas também toda a sociedade que as compõe.

Como resultado da Conferência, a sua Plataforma de Ação foi um documento criado por parte dos governos no sentido de auxiliar na implementação de políticas publicas para as mulheres. Entre os dez compromissos estabelecidos neste documento, está o de: "(...) promover o pleno respeito pela dignidade humana e alcançar a igualdade e a equidade entre homens e mulheres através do aumento da participação e da liderança da mulher na vida política, civil, econômica, social, cultural e no desenvolvimento" (NAÇÕES UNIDAS, 1995: 31).

Uma das esferas discutidas pelos governantes nesta Plataforma ${ }^{4}$ foi a participação da mulher no mercado de trabalho. Para que fosse efetivada essa

3 Quinto conclave da agenda social das Nações Unidas da década de 1990, a IV Conferência Mundial sobre a Mulher, realizada em Pequim (Beijing), de 4 a 15 de setembro de 1995, inseriu-se numa sequência bastante regular de grandes encontros sobre o tema, inaugurada em 1975 por iniciativa e impulsão do próprio movimento de mulheres (ALVES, 2001: 211). A Conferência de Beijing contou com a participação de 180 delegações governamentais e 2.500 organizações não-governamentais (NAÇÕES UNIDAS, 1995).

${ }_{4} \quad O$ principal documento oriundo da IV Conferência Mundial sobre a Mulher é a Plataforma de Ação, cujo escopo cobre virtualmente todos os campos de interesse para a situação da mulher no mundo e nas respectivas sociedades. Por sua abrangência e volume, constitui o mais completo diagnóstico internacional sobre a matéria e o mais pormenorizado guia para as ações a serem tomadas por Estados, organizações governamentais e nãogovernamentais, meios de comunicação, famílias e indivíduos, para a superação das discriminações de gênero (ALVES, 2001: 220). 


\section{Artigo original}

Hegemonia - Revista Eletrônica de Relações Internacionais do Centro Universitário Unieuro

ISSN: $1809-1261$

UNIEURO, Brasília, número 11, 2013, pp. 166-199

ação foi solicitado aos governos, a comunidade internacional, a sociedade civil (dentre elas as organizações não-governamentais) que adotassem medidas de cunho decisório com a preocupação em relação às desigualdades nas estruturas políticas e econômicas.

Algumas estratégias do documento gerado em território chinês, em relação a gênero e trabalho, objetivaram a promoção da independência e dos direitos econômicos das mulheres. Além disso, promoveu o acesso ao emprego; às condições de trabalho apropriadas; o controle dos recursos econômicos; adoção de medidas pelos governos que garantam os direitos de equidade salarial entre os gêneros. A aprovação e a aplicação de leis contra a discriminação por motivos de sexo no mercado de trabalho. Ações como essas também visam a plena participação feminina, as quais geram condições de igualdade na formulação de políticas e na definição de estruturas governamentais que ampliem essas conquistas sociais. Desse modo, concretizam-se ações que outorguem à mulher direitos iguais aos dos homens aos recursos econômicos; entre outros.

A partir desses objetivos traçados na Conferência, o governo brasileiro passou a ser um dos signatários do documento. Essas ações são um grande desafio para o país, já que pesquisas do Fórum Econômico Mundial apontam que entre 128 países, o Brasil ocupa o $74^{\circ}$ lugar na disparidade entre os sexos (ANISTIA INTERNACIONAL, 21/06/2011).

No Brasil, o movimento feminista já reunia mulheres desde a década de 1980 no sentido de discutir a situação feminina no país. Entretanto, a preparação para Conferência de Beijing foi o primeiro passo para que as organizações não-governamentais e movimentos sociais buscassem a nível nacional a construção de uma visão mais aprofundada do movimento feminista brasileiro. Dessa forma, esse evento internacional influenciou a primeira tentativa da elaboração de um documento nacional sobre o tema. No processo oficial de atividades de elaboração do relatório brasileiro para a conferência, 


\section{Artigo original}

Hegemonia - Revista Eletrônica de Relações Internacionais do Centro Universitário Unieuro

ISSN: $1809-1261$

UNIEURO, Brasília, número 11, 2013, pp. 166-199

um dos principais temas foi a participação da mulher no mercado de trabalho. A preparação dos líderes regionais para a conferência ocorreu pela primeira vez num processo de consulta na elaboração de um relatório sobre a vida das mulheres na região.

Após a conferência, algumas ações relacionadas a políticas públicas de gênero foram tomadas pelo estado brasileiro. Um importante marco foi a criação da Secretaria de Políticas para as Mulheres (SPM), o que está em consonância com os objetivos estratégicos de Beijing. Esse órgão é ligado à Presidência da República, a SPM e traçou seus objetivos no sentido de:

(...) assessorar de forma direta o Presidente da República na formulação e articulação de políticas para as mulheres; elaborar campanhas educativas e o planejamento sobre questões de gênero que refletem diretamente nas ações do governo, bem como de outras esferas públicas; cooperar na promoção de igualdade de gênero; promover cooperação com organismos nacionais e internacionais, públicos e privados, direcionados às implementações de políticas de gênero; acompanhar a implementação de legislação de ação afirmativa e definição de ações públicas que visem o cumprimento de acordos, convenções e planos de ação assinados pelo Brasil, relacionados à igualdade de gênero e de combate à discriminação (REPÚBLICA DO BRASIL, 21/06/2011).

Criada no ano de 2002, ela foi legitimada como instrumento do Governo. Já em 2003, por meio da Medida Provisória 103, de $1^{\circ}$ de janeiro, convertida na Lei $n^{\circ}$ 10.683, de 2003, para desenvolver ações conjuntas com todos os Ministérios e Secretarias Especiais, teve como desafio a incorporação das especificidades das mulheres nas políticas públicas e o estabelecimento das condições necessárias para a sua plena cidadania. Dessa forma, ela passou a integrar a estrutura da Presidência da República como órgão essencial, o que já sinalizava a preocupação do Estado brasileiro com a questão de gênero. 
Artigo original

Hegemonia - Revista Eletrônica de Relações Internacionais do Centro Universitário Unieuro

ISSN: $1809-1261$

UNIEURO, Brasília, número 11, 2013, pp. 166-199

Existem três subsecretarias que se dividem por temas: a Articulação Institucional e Ações Temáticas, Enfrentamento à violência contra as mulheres e Planejamento e Gestão. Os temas relacionados à educação, saúde e trabalho são de competência da Subsecretaria de Articulação Institucional e Ações temáticas. Ela promove a articulação e a integração entre órgãos públicos visando a concretização de ações nessas temáticas, fiscaliza o cumprimento da legislação e também desenvolve programas de monitoração de projetos, atividades e ações nessas áreas.

São quatro as ações relacionadas à temática trabalho que a Subsecretaria promove sob a Coordenação Geral de Programas e Ações de Trabalho: Programa Pró Equidade de Gênero, Programa Trabalho e Empreendedorismo da Mulher, Programa Mulheres Construindo na Construção Civil e Programa Trabalho, Artesanato, Turismo e Autonomia das Mulheres. A SPM também mantém uma articulação internacional bastante ampla relativa à questão dos direitos da mulher.

Por meio de vários tratados, acordos e conferências que o Brasil é signatário, a Conferência de Beijing representou um grande significado para a estipulação destes órgãos. Além da contribuição histórica dos movimentos sociais no país, os compromissos firmados internacionalmente pelo Brasil, principalmente, nessa Conferência, foram primordiais para a criação da SPM, o qual se tornou instrumento institucional considerado fundamental para a incorporação de políticas públicas específicas para as mulheres. Juntamente com a Presidência da República, a SPM também desenvolve ações conjuntas com a Secretaria Especial de Políticas de Promoção da Igualdade Racial (SEPPIR) e a Secretaria de Direitos Humanos (SEDH), o que representa um novo significado do tratamento do Estado brasileiro a cerca das desigualdades sociais concernentes a gênero e etnias.

Entre os destaques de um balanço das políticas públicas realizado por esse órgão, desde a sua criação, está a sua articulação dada a partir da 


\section{Artigo original}

Hegemonia - Revista Eletrônica de Relações Internacionais do Centro

Universitário Unieuro

ISSN: $1809-1261$

UNIEURO, Brasília, número 11, 2013, pp. 166-199

promulgação de 46 novos instrumentos normativos em benefício das mulheres brasileiras. Dentre elas, deve-se destacar a Lei Maria da Penha5, a ampliação da licença-maternidade para 180 dias e a mini-reforma eleitoral.

No campo do trabalho, a SPM lançou o I Plano Nacional de Políticas para as Mulheres em 2005, que trouxe um conjunto de 76 ações, dividas em prioridades como: ampliação do acesso das mulheres no mercado de trabalho; promoção da autonomia econômica e financeira das mulheres por meio do empreendedorismo, associativismo, cooperativismo e comércio; promoção de relações de trabalho não-discriminatórias com equidade salarial e de acesso a cargos de direção; garantia do cumprimento da legislação no âmbito do trabalho doméstico e estímulo à divisão das tarefas domésticas e ampliação do exercício da cidadania das mulheres e do acesso a terra e à moradia.

III. Os direitos das mulheres: a Conferência de Beijing e a Secretaria Especial para as Mulheres

Dentre as diversas diretrizes da Plataforma de Beijing, as quais foram concordadas pelos Estados signatários, está a diretriz relacionada à temática trabalho. Um dos temas mais discutidos na esfera do gênero pelos Estados foi uma maior igualdade entre homens e mulheres na esfera do trabalho. Tudo isso possibilitou que essa Plataforma tornar-se um importante instrumento a ser implementado pelos países em suas políticas públicas.

Durante os anos subseqüentes desse evento, algumas dessas diretrizes foram implementadas pelo Brasil. A criação da Secretaria Especial para as

5 A Lei $n^{\circ} 11.340$, de 7 de agosto de 2006, conhecida como Lei Maria da Penha cria mecanismos para coibir e prevenir a violência doméstica e familiar contra a mulher, nos termos do § 80 do art. 226 da Constituição Federal, da Convenção sobre a Eliminação de Todas as Formas de Violência contra a Mulher, da Convenção Interamericana para Prevenir, Punir e Erradicar a Violência contra a Mulher e de outros tratados internacionais ratificados pela República Federativa do Brasil; dispõe sobre a criação dos Juizados de Violência Doméstica e Familiar contra a Mulher; e estabelece medidas de assistência e proteção às mulheres em situação de violência doméstica e familiar (REPÚBLICA DO BRASIL, 20/06/2011). 


\section{Artigo original}

Hegemonia - Revista Eletrônica de Relações Internacionais do Centro

Universitário Unieuro

ISSN: $1809-1261$

UNIEURO, Brasília, número 11, 2013, pp. 166-199

Mulheres (SPM), que lançou o Plano Nacional de Políticas para as Mulheres $(P N P M)^{6}$ com diversas proposições nas áreas de gênero é um claro avanço dessas conquistas sociais. O emponderamento feminino na política, a educação, entre outras são alguns sinais que demonstram tais transformações.

No entanto, tratarei, neste artigo, apenas a temática do trabalho sob a perspectiva de programas do PNPM de que visam ampliar o acesso das mulheres aos recursos produtivos como a terra, o crédito e a assistência técnica. Esses programas são destinados às mulheres desempregadas ou que estão inseridas na economia informal.

O Ministério do Desenvolvimento Agrário em conjunto com a SPM vêm tentando implementar ações no âmbito da agricultura familiar sob o ângulo objetivos estratégicos em conformidade com a Plataforma de Ação de Beijing:

Aumentar a capacitação técnica, em administração, extensão agrária e comercialização para a mulher na agricultura; criar e modificar programas que reconheçam e fortaleçam o papel decisivo da mulher na segurança alimentar; proporcionar às produtoras remuneradas e não remuneradas, especialmente às que se dedicam às atividades de produção de alimentos, como a agricultura, assim como as empresas urbanas, igualdade de acesso a tecnologias apropriadas, transportem serviços de extensão, comercialização e facilidades de crédito a nível local e comunitário (NAÇÕES UNIDAS, 1995: 31-76)

Nesse contexto, o Governo Federal começou a integrar em suas políticas públicas um novo viés diante de um novo olhar a cerca do tema gênero. Políticas consideradas "gerais" para a população começaram a constituir equipe de assessoria e recursos para a promoção de políticas de igualdade. Se instituiu um novo objetivo: transversalizar as relações de gênero nas políticas

O Plano Nacional de Políticas para as Mulheres foi lançado no ano de 2004 por um grupo de trabalho interministerial, no qual se estabeleceu diretrizes que deveriam orientar a atuação estatal na construção de políticas públicas sob os princípios de igualdade e respeito à diversidade (REPÚBLICA DO BRASIL, 2009). 


\section{Artigo original}

Hegemonia - Revista Eletrônica de Relações Internacionais do Centro

Universitário Unieuro

ISSN: $1809-1261$

UNIEURO, Brasília, número 11, 2013, pp. 166-199

de desenvolvimento rural, para que as mulheres também alcançassem direitos econômicos e um maior exercício da cidadania.

IV. Estatísticas oficiais sobre as mulheres rurais - especificidade do trabalho feminino no campo

O Programa Nacional de Fortalecimento da Agricultura Familiar (Pronaf) ${ }^{7}$, que antes trabalhava na questão da agricultura para a sociedade em geral, teve seu orçamento ampliado destinado às políticas públicas para as mulheres rurais através da extensão do Programa Pronaf-Mulher, o qual possui objetivo maior de oferecer assistência técnica e créditos para as mulheres que trabalham no meio rural. No entanto, essas mudanças não refletiram de maneira direta na vida das mesmas, já que a posição da mulher na estrutura família é secundária e ainda persiste a invisibilidade e o seu trabalho produtivo, o qual é considerado apenas como "ajuda" aos ofícios desempenhados pelos homens.

Em se tratando de cooperação técnica internacional no mesmo período, percebe-se uma característica semelhante à situação interna. Os projetos e programas são elaborados também sob uma perspectiva de gênero, mas as mesmas não alcançam resultados satisfatórios ou plenos no sentido de emancipar as mulheres na igualdade de gênero. O Instituto Interamericano de Cooperação para a Agricultura (IICA) formula projetos de cooperação técnica na agricultura juntamente com o governo brasileiro. Todavia, apesar da temática de gênero ser tratada com objetivos bastante claros, esses programas não conseguem beneficiar de forma mais eficaz as mulheres, assim

7 O Programa Nacional de Fortalecimento da Agricultura Familiar (Pronaf) financia projetos individuais ou coletivos, que gerem renda aos agricultores familiares e assentados da reforma agrária. O programa possui as mais baixas taxas de juros dos financiamentos rurais, além das menores taxas de inadimplência entre os sistemas de crédito do país. 
Artigo original

Hegemonia - Revista Eletrônica de Relações Internacionais do Centro Universitário Unieuro

ISSN: $1809-1261$

UNIEURO, Brasília, número 11, 2013, pp. 166-199

como acontece com o sexo oposto.

A discussão sobre o emponderamento da mulher no mercado de trabalho é tema de grande parte das discussões em fóruns e em organizações internacionais. Mesmo assim, o Brasil ainda não conseguiu assimilar de forma concreta essas diretrizes em suas políticas internas. Existem pequenos avanços no mercado de trabalho brasileiro sob o ângulo de gênero, tais como mostram as Pesquisas de Amostra por Domicílio (PNAD) realizadas pelo Instituto Brasileiro de Geografia e Estatísticas (IBGE), entre os anos de 1990 até meados da década atual (DI SABBATO, 2009).

Uma das formas de atuação da Conferência de Beijing era influenciar os resultados práticos no Brasil na produção de estatísticas oficiais sobre a situação das mulheres rurais. Essas informações fazem parte de compromissos internacionais celebrados entre o governo e diversos órgãos internacionais que contribuem para a avaliação dos resultados de proposições desse evento. Além disso, constituem como ferramentas importantes para traçar estratégias de ação do Estado na implementação de políticas públicas. Apesar dessa importância, só recentemente é que esses dados estatísticos se materializaram no sentido de funcionarem como instrumentos de elaboração de políticas públicas.

A partir dos anos 2000, é que uma nova maneira de fazer pesquisas oficiais foi influenciada pelos organismos internacionais no sentido de criar possibilidades de uma nova perspectiva para o debate acerca da invisibilidade, bem como sobre produção sem remuneração e de autoconsumo relacionado à agricultura familiar sob o ângulo de gênero e sua incorporação nas estatísticas do governo federal. No entanto, a realização dessas estatísticas encontram muitos limites para que tais análises quantitativas sejam de fato realizadas. A dificuldade encontrada está relacionada ao fato de que nas pesquisas sobre a agricultura familiar conclui-se que essa é uma atividade econômica aonde as estatísticas oficiais, não existe a categoria profissional "trabalhador familiar". 


\section{Artigo original}

Hegemonia - Revista Eletrônica de Relações Internacionais do Centro Universitário Unieuro

ISSN: $1809-1261$

UNIEURO, Brasília, número 11, 2013, pp. 166-199

Quer dizer, nas estatísticas, a esposa e os filhos aparecem apenas como "membros não remunerados da família", o que dificulta ainda mais um conhecimento mais profundo do governo sobre a situação feminina no campo.

Mesmo com a implementação de políticas públicas no meio rural sob a perspectiva de gênero, como o Pronaf-Mulher, nota-se grande queda na ocupação rural feminina. Uma das dificuldades de implementação de ações afirmativas no meio rural é o fato de que há uma grande diferença no modo de trabalho entre mulheres rurais e urbanas. Enquanto as trabalhadoras urbanas saem de casa para realizar suas tarefas extra-casa, no campo, essa mesma situação aparece de forma diversa. Como o trabalho dessas mulheres é realizado na horta e no quintal, muitas vezes não existem distinções de jornadas de trabalho.

Dessa forma, há uma mudança muito lenta em relação à ocupação, remuneração e direito a terra no quesito de igualdade entre homens e mulheres. Mas mesmo que essas mudanças sejam quase imperceptíveis, existe grande participação das trabalhadoras rurais por meio de reivindicações no cenário político brasileiro.

As estatísticas também mostram outros limites de implementação de ações afirmativas de gênero no meio rural. A taxa de famílias chefiadas por mulheres no campo é relativamente baixa, são somente $16,2 \%$, embora, ao logo dos anos, lentamente vem aumentando a taxa de participação das mulheres como responsáveis pela família (DI SABATTO, 2009: 83). Essa porcentagem reflete o modo de como os laços patriarcais ainda se mostram fortes na sociedade rural. Nota-se uma masculinização do campo, o que dificulta as ações do governo na área rural.

Outro limite notado nessas estatísticas é o fato de haver maior número de filhos homens do que filhas mulheres nos domicílios rurais. Dados de 2006, mostram que as filhas mulheres são apenas $18,1 \%$ dos filhos das famílias ocupadas com a agropecuária. Houve um ligeiro acréscimo comparado aos 
Artigo original

Hegemonia - Revista Eletrônica de Relações Internacionais do Centro Universitário Unieuro

ISSN: $1809-1261$

UNIEURO, Brasília, número 11, 2013, pp. 166-199

dados de 2004, quando a porcentagem era de 17,5\% (DI SABATTO, 2009: 8283).

Assim, o motivo que explica tão baixo número de filhas mulheres residindo em domicílios rurais é fato de que a migração das filhas para a cidade vem aumentando a cada ano. A profunda desvalorização do papel feminino pela sociedade rural brasileira, mesmo com os esforços do governo em suas ações afirmativas, contribui para esse êxodo das mulheres no campo.

Analisando a diferenciação do trabalho masculino e feminino no meio rural por meio dos dados do IBGE de 1995-1996, conclui-se que os homens são os maiores responsáveis pelo setor da lavoura e da pecuária brasileira (atividade que representa $83,8 \%$ do valor total da produção agropecuária). Isso significa que a ocupação rural é pesadamente uma atividade realizada pelos homens enquanto as mulheres participam apenas como membros da família (DI SABATTO El alli 2009: 89).

As posições de homens e mulheres na ocupação rural revelam que são quantificadas, na maior parte, as atividades realizadas na agropecuária (70\% no total). Enquanto as atividades de agricultura familiar, como o cuidado de aves, hortas e pequenos animais, realizadas em sua maior partem por mulheres, são consideradas como atividades de autoconsumo, o que não gera salário e renda é quantificada de forma indireta incluída em outras atividades do campo (DI SABATTO, 2009: 89). Essa interpretação mostra o papel subordinado da mulher e a dificuldade de se coletar dados nas posições de homens e mulheres no mercado de trabalho rural brasileiro. Esses dados expressam que as mulheres trabalham, mas não obtêm rendimentos monetários com em suas atitudes.

Segundo as estatísticas rurais, a forte presença feminina na ocupação rural está concentrada no trabalho não remunerado e no autoconsumo. Estas são atividades comandadas pela lógica do trabalho familiar aparentemente ainda presente no meio rural: o chefe da família é o marido e pai provedor. As 


\section{Artigo original}

Hegemonia - Revista Eletrônica de Relações Internacionais do Centro Universitário Unieuro

ISSN: $1809-1261$

UNIEURO, Brasília, número 11, 2013, pp. 166-199

mulheres de cada família trabalham, mas os rendimentos são do chefe. Esses números podem ser vistos em estatística na qual a realidade revela que 2/3 das mulheres rurais continuam trabalhando apenas para "ajudar" a família na forma de trabalho sem remuneração ou plantando, colhendo, cuidando de pequenos animais para o autoconsumo familiar (DI SABATTO, 2009: 89).

Surge, então, outra estatística no mundo do mercado de trabalho rural feminino: a jornada de trabalho masculina é, em média, acima de 39 horas semanais, enquanto as mulheres apresentam uma média um pouco superior à metade da jornada masculina, uma jornada de 21,7 horas semanais. Por meio dessas informações uma importante questão aparece como incógnita para explicar os limites das ações afirmativas no meio rural feminino: por que as mulheres declaram uma jornada de trabalho tão inferior ao padrão feminino? Talvez, isso pode ser explicado pela forte presença de trabalho para autoconsumo praticado pela mulher nas atividades rurais que camufla a extensão de sua jornada.

Entre os anos de 1993 a 2001, cerca de 79\% das trabalhadoras rurais não auferiram rendas monetárias. Em 2004 essa taxa de remuneração caiu para 74,9\%, mas em 2006 voltou para a mesma porcentagem dos anos anteriores. Isso nos dá uma pista sobre o drama que as mulheres vivem no campo, já que a proporção de trabalhadores homens sem remuneração é de apenas $26,2 \%$ nos mesmos anos. Esses dados nos permitem concluir que nas atividades realizadas pelas mulheres no âmbito da lavoura e na pecuária, elas se destacam como coadjuvantes do trabalho masculino, mantendo ainda mais o seu papel no meio rural como extensão do trabalho na estrutura familiar. Essa característica dificulta ainda mais o trabalho do governo em quantificar as mulheres na agricultura no sentido de desenvolver e implementar políticas públicas realmente capazes de mudar a realidade feminina no meio rural (DI SABATTO, 2009: 116).

A discriminação do papel social feminino acontece em larga escala no 


\section{Artigo original}

Hegemonia - Revista Eletrônica de Relações Internacionais do Centro Universitário Unieuro

ISSN: $1809-1261$

UNIEURO, Brasília, número 11, 2013, pp. 166-199

meio rural. Isso é refletido por meio do grande contingente de mulheres trabalhando sem remuneração com menos possibilidade de autonomia econômica. As atividades ligadas à esfera produtivas são desempenhadas pelos homens, enquanto as mulheres desempenham atividades da esfera reprodutiva. O resultado dessa divisão de papéis é a maior valorização do trabalho masculino, enquanto eles exercem as atividades de maior valor agregado.

Nota-se que "a presença das mulheres no trabalho assalariado ou no campo não alterou em nada a responsabilidade quase exclusiva pelo trabalho doméstico e o cuidado" (DI SABATTO, 2009: 18). Por meio dessa formulação, é possível abordar que, para as mulheres, a realização dos trabalhos domésticos e de cuidados, coloca-se como parte 'natural' de sua identidade. Essa identidade é cada vez mais legitimada pelas funções maternas e valores que se associam a docilidade, fragilidade, compreensão, carinho e afeto. Esse discurso ideológico contribui para que a mulher continue fazendo o trabalho doméstico. No campo, essa divisão sexual do trabalho é nítida sobre o que é realizado no âmbito da casa e no roçado. As atividades produtivas realizadas pelas mulheres continuam sendo consideradas uma extensão do trabalho doméstico.

A mudança na cultura da divisão sexual do trabalho no campo é um dos principais desafios do governo para que as mulheres sejam inseridas no mercado de trabalho e na economia brasileira. No meio rural, as desigualdades de gênero são muito mais visíveis do que no urbano. As mulheres urbanas possuem um nível de escolaridade melhor tanto em relação às mulheres rurais, quanto aos homens urbanos. Mesmo que as mulheres urbanas desempenhem trabalhos domésticos, há uma melhor remuneração e reconhecimento de seu papel no mercado de trabalho. À medida que se aumenta o nível de escolaridade e renda, diminui a jornada de trabalho para as mulheres urbanas. Destaca-se, então, o problema da invisibilidade das trabalhadoras rurais que provoca diversas barreiras às políticas afirmativas implementadas. 
Artigo original

Hegemonia - Revista Eletrônica de Relações Internacionais do Centro Universitário Unieuro

ISSN: $1809-1261$

UNIEURO, Brasília, número 11, 2013, pp. 166-199

V. Limites e possibilidades do Pronaf-Mulher

Quais, então, são as reais possibilidades de políticas de ações afirmativas, como o Pronaf-Mulher? A partir do momento que o Estado reconhece a problemática é possível traçar um novo horizonte. Um dos principais desafios para a sociedade civil é a proteção dos direitos humanos, mas os Estados e a sociedade civil estão melhor aparelhados graças à dinâmica estabelecida pelos ciclos das conferências. Embora a indivisibilidade dos direitos humanos tenha sido aceita como um princípio pelos Estados, assim como a democracia reconhecida como o regime político ideal para a realização das liberdades fundamentais, a realização de conferências como a de Beijing, ainda permanece um descompasso e tensões para as garantias desses direitos como indica do Relatório de Desenvolvimento Humano 2000, do PNUD. As tensões entre universalidade dos direitos e especificidade cultural; entre a soberania nacional e controle e monitoramente internacional dos direitos humanos no interior de cada país; entre a supremacia das leis internacionais e das leis nacionais; entre a ratificação das leis internacionais e sua implementação são os fatores sociais que dificultam a igualdade dentre gêneros (ALVEZ, 2001).

Dessa forma, a conferência de Beijing, estabelece como fundamental o monitoramento da implementação dos direitos das mulheres, o que causa certo constrangimento por parte dos Estados, já que um compromisso internacional foi assumido e, nesse âmbito, deve ser cumprido de alguma forma. Os grandes encontros internacionais da década de 1990 deram margem a declarações políticas coletivamente aprovadas, porém mais conceituais do que propriamente programáticas, em que fixam os compromissos dos participantes, quase sempre a nível de chefes de Estado ou de Governo a implementação dos respectivos programas de ação se dá de modo irrisório. 


\section{Artigo original}

Hegemonia - Revista Eletrônica de Relações Internacionais do Centro Universitário Unieuro

ISSN: $1809-1261$

UNIEURO, Brasília, número 11, 2013, pp. 166-199

As ações e necessidades da sociedade civil, como a de mulheres inseridas na agricultura brasileira, foram essenciais para que essa conferência multilateral legitimasse a presença do tema gênero de mercado de trabalho na agenda internacional como um tema global, considerado antes como matéria exclusiva das jurisdições nacionais.

É, em parte, nesse âmbito que o Brasil tem uma intensa participação nos foros diplomáticos parlamentares no sentido de fortalecer as práticas democráticas internas de acordo com proposições internacionais, bem como as das conferências sobre temas vitais que se tornaram globais, exigindo um tratamento coletivo e colaboração universal.

As estatísticas oficiais elaboradas pelo governo federal com a colaboração de diversas organizações internacionais fazem parte do compromisso que o Brasil firmou na Conferência de Beijing para apresentar relatórios sobre os esforços nacionais empreendidos nas matérias tratadas entre os Estados. O país reconheceu de maneira consensual o dever de prestar contas à comunidade internacional sobre sua atuação doméstica nesse tema. Acontecimento político que antes era considerado competência soberana irrestrita; legitimou, dessa forma, o seu monitoramento pela ONU.

Então, por que o Brasil, um país democrático e que tem uma grande participação nos foros internacionais, como um Estado interessado na construção dos valores de direitos humanos, não incorpora as políticas de gênero de uma forma que encontre melhores resultados no alcance das trabalhadoras no contexto rural?

Nota-se que as políticas de ações afirmativas no Brasil ainda são novas e estão em construção e aperfeiçoamento. É importante ressaltar que a Plataforma de Beijing é um documento recomendatório e não um instrumento jurídico de direito internacional. Isso quer dizer que a Plataforma faz recomendações para os países e não os obriga a cumprir uma norma de Direito. 


\section{Artigo original}

Hegemonia - Revista Eletrônica de Relações Internacionais do Centro Universitário Unieuro

ISSN: $1809-1261$

UNIEURO, Brasília, número 11, 2013, pp. 166-199

No entanto, se esse documento for apreciado com devido valor pelos países, ele pode se transformar em um rico instrumento na construção e implementação de políticas públicas ou até mesmo em instrumentos semijurídicos de cobranças, inclusive internacionais e referência para ações cooperativas. Essa ação se tem comprovado cada dia mais necessária para conter o rastro excludente e destrutivo do processo de globalização sem controle do mundo após a Guerra Fria (ALVES, 2001).

Por mais que a implementação de políticas afirmativas de gênero no Brasil caminhe de forma lenta, é possível notar alguns resultados positivos nas ações do Governo Federal. O programa governamental Pronaf-Mulher foi uma das ações de reconhecimento e autonomia para sustentar a inserção das mulheres nas políticas públicas de crédito rural no contexto da Agricultura Familiar. A agricultura é o espaço em que, talvez, se encontre as maiores desigualdades entre gênero, não somente aqui, mas em diversos outros países.

Um dos maiores resultados das desigualdades entre homens e mulheres no meio rural é o êxodo rural, sobretudo de mulheres jovens. Elas migram para as cidades em busca de melhores condições de vida, já que a invisibilidade do trabalho feminino é cada vez maior, tornando o campo palco de atuação apenas do homem.

Foi nesse contexto de invisibilidade da mulher no campo e das demandas dos movimentos sociais de mulheres, que o governo criou o Programa Pronaf-Mulher, sob o pressuposto de que através do crédito é possível gerir uma atividade própria que possibilite às mulheres contribuir para a renda familiar e repercutir na sua autonomia econômica, bem como permitir seu reconhecimento e uma maior participação política (HERNÁNDEZ, 2010).

É possível notar por meio das estatísticas do PNAD, uma pequena, mas real elevação dos rendimentos das mulheres rurais entre 2004 e 2006, época 
Artigo original

Hegemonia - Revista Eletrônica de Relações Internacionais do Centro Universitário Unieuro

ISSN: $1809-1261$

UNIEURO, Brasília, número 11, 2013, pp. 166-199

da implementação do programa. Houve um crescimento de $31,5 \%$ desses rendimentos entre esses períodos. Esses resultados, possivelmente, estão relacionados ao financiamento para a agricultura familiar feito pelo Pronaf. Talvez, essa pequena expansão dos rendimentos femininos na ocupação expresse uma mudança cultural e comportamental em relação ao papel das mulheres, que na vida urbana já está mais avançada e que lentamente penetra no meio rural (DI SABATTO, 2009: 105-116).

Para que as mudanças culturais sobre o papel da mulher no meio rural continuem ocorrendo é necessário que se reconheça a sua autonomia econômica. Deve-se levar em conta a sua capacidade de gerar renda e de decidir tanto sobre a forma como essa renda é utilizada quanto a gastos em relação aos próprios e familiares (HERNÁNDEZ, 2010).

É através do reconhecimento que os indivíduos podem garantir a plena realização de suas capacidades e uma autorrelação marcada pela integridade. Nancy Fraser (apud HERNÁDEZ, 2010) considera que o reconhecimento é uma questão de justiça que requer tanto de políticas públicas de redistribuição para responder às injustiças de ordem econômica, quanto de reconhecimento para as injustiças de ordem cultural. Nesse sentido, é necessário que ocorra uma expansão de liberdades, uma expansão de liberdades construtiva, que resultem no desenvolvimento de capacidades das mulheres de levar o tipo de vida que elas valorizam com uma ampla decisão.

Essas capacidades podem ser aumentadas por meio de políticas públicas, como também, o encaminhamento dessa política pode ser influenciado pelo uso efetivo das capacidades participativas da sociedade. Dessa forma, é possível reconhecer algumas possibilidades do Pronaf-Mulher que constitui uma forma de reconhecimento e autonomia para as mulheres rurais no contexto da agricultura familiar, apesar dos pequenos efeitos que ainda acontecem após a sua implementação.

O Pronaf foi criado em 1996 e representou um importante marco na 


\section{Artigo original}

Hegemonia - Revista Eletrônica de Relações Internacionais do Centro Universitário Unieuro

ISSN: $1809-1261$

UNIEURO, Brasília, número 11, 2013, pp. 166-199

esfera de políticas públicas brasileiras, pois significou, na prática, o reconhecimento do Estado das especificidades de uma nova categoria social. Agora, os agricultores familiares, que antes eram considerados somente como agricultores de subsistência têm visibilidade as atenções governamentais. Além disso, o governo adotou uma política ainda mais inclusiva, quando criou um programa específico para as mulheres no campo, o Pronaf-Mulher. A partir daí, as mulheres poderiam ter a sua autonomia expandida, já que no contexto geral do Pronaf, elas tinham um acesso limitado a esse programa. Nesse sentido, o programa objetivou a ampliação das oportunidades das mulheres na obtenção de um crédito específico para as mulheres rurais, para promover sua autonomia e ampliar o grau de sua participação na sociedade.

O objetivo do Ministério do Desenvolvimento Agrário (MDA), por meio da criação do Pronaf-Mulher, era de promover a autonomia das mulheres no contexto rural através da ampliação das oportunidades às mulheres na obtenção do crédito rural. A meta para alcançar esse objetivo seria a representação das mulheres em $30 \%$ na distribuição de créditos do Pronaf, pois se calculava que até então o programa contava com apenas $7 \%$ de mulheres entre seus beneficiários. Como já foi citado anteriormente, os resultados das políticas públicas de igualdade de gênero são lentos, no entanto, apesar desta meta ainda não ter sido atingida, a participação das mulheres na obtenção de créditos vem aumentando (SCOTT, 2010: 100).

Embora haja pequenos avanços, no que diz respeito a melhoria da situação das mulheres do campo em estatísticas oficiais, está acontecendo uma mudança cultural a partir da implementação de ações afirmativas como o Pronaf-Mulher. É possível notar essa mudança cultural, por exemplo, na importância da obtenção de créditos pelas mulheres agricultoras, que não se reduz apenas em uma contribuição que sustenta a economia familiar, mas sim, como uma forma de reconhecimento dos direitos conquistados por essas mulheres. Uma forma de se sentirem mais valorizadas e por serem levadas 


\section{Artigo original}

Hegemonia - Revista Eletrônica de Relações Internacionais do Centro Universitário Unieuro

ISSN: $1809-1261$

UNIEURO, Brasília, número 11, 2013, pp. 166-199

em consideração pelo Estado. Isso não é somente percebida pelas mulheres, mas pode significar uma ponte para as mudanças nas relações de trabalho entre homens e mulheres. A possibilidade da diminuição de diferenças que se constroem entre as atividades das mulheres e dos homens sob a perspectiva da divisão sexual do trabalho. Em outros termos, pode-se afirmar que tarefas construídas socialmente, 'devem ser próprias do homem e da mulher'.

Outra importante mudança cultural que ocorre é o fato das mulheres se preocuparem com a documentação e o Estado, o que mais uma vez, deve proporcionar o acesso. Assim, para se obter o crédito do programa, é necessário que essas mulheres tenham documentação pessoal. Isso permitiu um maior reconhecimento de sua autonomia e a possibilidade de desenvolver uma independência, pois o processo de negociação para obtenção de créditos seria realizado por elas e não mais somente por seus maridos.

O programa também incentiva as mulheres, por meio de cursos, a valorizar o seu produto para uma melhor escala de qualidade, o que proporciona a elas competirem no mercado em maior igualdade com os homens. Desse modo, as mulheres podem ser inseridas no mercado de trabalho gradualmente e então, obterem mais confiança e melhor preparado técnico para uma maior equidade de gênero. Ações como essas provocam pequenas mudanças culturais que podem possibilitar uma maior igualdade de gênero em contextos rurais. As mudanças não serão vistas a curto prazo, pois existe uma cultura da divisão sexual do trabalho na sociedade e, no meio rural, isso é ainda mais visível.

Um importante passo para que essas mudanças culturais pudessem acontecer de fato na sociedade, foi o reconhecimento, por parte do Estado, da necessidade da equidade de gênero. O Brasil é signatário dos principais tratados de direitos humanos, como a Conferência de Beijing, e as ações afirmativas promovidas no país, refletem a tentativa de adequação dos instrumentos internacionais. É importante ressaltar que as mudanças culturais 


\section{Artigo original}

Hegemonia - Revista Eletrônica de Relações Internacionais do Centro

Universitário Unieuro

ISSN: $1809-1261$

UNIEURO, Brasília, número 11, 2013, pp. 166-199

não ocorrem somente por parte do Estado, mas a sociedade civil tem um importante papel no sentido de buscar uma agenda. Nesse caso específico, uma agenda de gênero para uma promoção de igualdade na construção de um debate entre sociedade e Estado. Da mesma forma, uma conferência internacional, como a de Beijing, talvez tenha um papel muito mais importante na mudança cultural de uma sociedade através das ações do governo que se adéquam, em diferentes medidas, às proposições nela apresentadas:

O objetivo da Plataforma de Ação, em plena conformidade com os princípios da Carta das Nações Unidas e o direito internacional é o empowerment de todas as mulheres. A plena realização de todos os direitos humanos e liberdades fundamentais de todas as mulheres é essencial para o empowerment das mulheres. Ao mesmo tempo em que a importância das particularidades nacionais e regionais e os diversos contextos históricos, culturais e religiosos devem ser levados em consideração, é dever dos Estados, independentemente de seus sistemas políticos, econômicos e culturais, promover e proteger todos os direitos humanos e liberdades fundamentais. A implementação desta Plataforma, inclusive através das legislações nacionais e da formulação de estratégias, políticas, programas e prioridades, é de responsabilidade soberana de cada Estado, em conformidade com todos os direitos humanos e liberdades fundamentais, e a importância e o pleno respeito pelos diversos valores éticos, contextos culturais e convicções filosóficas dos indivíduos e suas comunidades devem contribuir para o pleno gozo pelas mulheres de seus direitos humanos, com vistas a alcançarem igualdade, desenvolvimento e paz (ALVES, 2001: 222-223).

A temática gênero se tornou uma preocupação global legitimada pelas diversas conferências realizadas sob essas perspectivas. Os problemas relacionados ao tema ainda não se acham totalmente superados e, talvez, isso ainda esteja longe de acontecer. No entanto, é perceptível as pequenas 


\section{Artigo original}

Hegemonia - Revista Eletrônica de Relações Internacionais do Centro Universitário Unieuro

ISSN: $1809-1261$

UNIEURO, Brasília, número 11, 2013, pp. 166-199

mudanças provocadas na sociedade, tanto pelas demandas feministas, quanto pelas ações promovidas pelo Estado. As agências de monitoramento da ONU contribuem, de certa forma, em seus relatórios periódicos, sobre quais são e como são os resultados obtidos pelo Brasil da implementação de ações afirmativas em consonância com as proposições da Plataforma de Beijing.

A discussão em escala domestica passa a ter espaço em discussões políticas bilaterais, resultando em um círculo em que questões domésticas influenciam questões externas e vive-versa. Nesse sentido, é importante que os países se encaixem no molde de uma sociedade mais igualitária e com objetivos democráticos para uma melhor construção dos direitos humanos. No caso específico das mulheres rurais no Brasil, é necessário que o Estado esteja cada vez mas entrelaçado a essas novas questões mundiais para que os espaços mais difíceis de serem alcançados, como a agricultura feminina, sejam, de fato, beneficiados.

\section{Considerações Finais}

A implementação de ações afirmativas de gênero no Brasil, sob a perspectiva da Conferência de Beijing, bem como os seus resultados se dão de modo gradual frente as dificuldades sócio-culturais que o país enfrenta para efetivar ações que promovam o trabalho feminino no campo - algo que ainda está sendo construído na região.

O processo de reconhecimento da autonomia da mulher, por parte do Estado e pela sociedade, acontece de modo insuficiente, já que as necessidades femininas por igualdade salarial e de postos de trabalho tem uma intensidade tal que perdura nos dados estatísticos atuais sobre essa situação. As mudanças advindas do documento internacional acontecem, porém é necessário que haja uma mudança radical na cultura brasileira no modo de conceber o oficio feminino no campo para que seja alcançado 
Artigo original

Hegemonia - Revista Eletrônica de Relações Internacionais do Centro

Universitário Unieuro

ISSN: $1809-1261$

UNIEURO, Brasília, número 11, 2013, pp. 166-199

resultados mais expressivos.

A divisão sexual do trabalho ainda é visível na sociedade atual, mas as demandas femininas por equidade de gênero ultrapassou o espaço doméstico e tornou-se um tema global. A Conferência de Beijing, por meio de seus documentos, assinados pelo Brasil, propõe diversas orientações que viabilizam o reconhecimento da autonomia feminina, bem como a sua maior participação em uma sociedade democrática.

Mesmo que os documentos resultantes desse evento internacional não sejam um instrumento jurídico de coerção para o não cumprimento de suas proposições, o Brasil se esforça por meio de programas de ações afirmativas, como o Pronaf-Mulher para se adequar as exigências propostas internacionalmente. Esse programa de política pública consegue atualmente oferecer assistência técnica e créditos as mulheres rurais. No entanto, os seus resultados não são notados a curto prazo. Existem grandes barreiras no meio rural feminino para que tais medidas possam ser colocadas em prática através das políticas públicas de equidade de gênero lançadas pelo governo nos últimos anos.

A invisibilidade do trabalho feminino no campo é um dos grandes fatores que impedem melhores resultados dessas políticas afirmativas. 0 trabalho da mulher na zona rural continua sendo reconhecido apenas como "ajuda" ao trabalho "culturalmente" pertencente ao homem. Por mais que a iniciativa de reconhecimento do Estado seja refletida na criação e esforço de implementação de ações afirmativas, muitas vezes, esses programas não conseguem chegar a esses espaços, resultando em um processo ainda irrisório em seus resultados e mudanças concretas nas relações de trabalho no meio rural. Os fatores sociais gestados pela cultura patriarcal enraizada no seio da sociedade brasileira impedem que a mulher rompa com o seu papel de subserviência em relação ao homem na divisão sexual do trabalho no campo. A discriminação do papel social feminino acontece em grande escala no 


\section{Artigo original}

Hegemonia - Revista Eletrônica de Relações Internacionais do Centro Universitário Unieuro

ISSN: $1809-1261$

UNIEURO, Brasília, número 11, 2013, pp. 166-199

âmbito rural.

É necessário enxergar esses programas como importantes mecanismos de mudança cultural, no que diz respeito à divisão sexual do trabalho na sociedade. Os resultados são pequenos e muitas vezes existe até uma regressão da situação de desigualdades das mulheres no campo. Apesar desse déficit social, as políticas públicas e ações afirmativas em geral influenciadas pelos intuitos da Conferencia já começam a acontecer. Mesmo que de modo gradual, hoje ainda insuficientes ao espaço que pretendem preencher, as mulheres camponesas já alcançaram importantes conquistas de equidade na divisão sexual do trabalho amparadas pela administração pública e reconhecidas pela sociedade.

E para dar prosseguimento no avanço dessas conquistas sociais no campo é necessário que as agências internacionais de monitoramento continuem com a produção de relatórios periódicos sobre os resultados de implementação de ações afirmativas pelo Brasil, para que se analise os resultados obtidos e formas mais satisfatórias de implementação. Deve-se pensar na problemática de que esses compromissos firmados entre os líderes mundiais são muito mais conceituais do que propriamente programáticos, o que gera outro fator que inviabiliza ações práticas para a transformação da situação feminina.

O grande desafio do Brasil, bem como o da sociedade internacional que se reúne nos grandes encontros como a Conferencia, é colocar as questões domésticas, como a desigualdade de gênero, em um nível de mudança cultural global. Nesse quesito, são necessários diversos ajustes para que os instrumentos de diretrizes propostas nesses encontros obtenham resultados reais na sociedade.

Enfim, detecta-se que as políticas públicas de valorização do trabalho feminino no âmbito rural, as quais são influenciadas pela Conferencia de Beijing, ainda são recentes em território nacional e estão em construção - 


\section{Artigo original}

Hegemonia - Revista Eletrônica de Relações Internacionais do Centro Universitário Unieuro

ISSN: $1809-1261$

UNIEURO, Brasília, número 11, 2013, pp. 166-199

elas necessitam serem aperfeiçoadas. Por enfrentarem os vastos valores culturais que delimitam a função secundária do papel da mulher no trabalho em relação ao homem, as mudanças advindas das ações implementadas pelo Estado brasileiro se dá de modo gradual e ainda é insatisfatório frente as grandes demandas que geram conflitos nas áreas não urbanizadas do país. Apesar disso, dessa clara dificuldade, o esforço estatal tem sido presente e tem ganhado relativo crescimento em ações como a criação do Pronaf-Mulher para emancipar o gênero feminino em suas condições de trabalho. É evidente que, apesar das barreiras impostas, é perceptível que a administração pública brasileira tem tentado alcançar o patamar internacional de equidade na divisão social do trabalho entre gêneros propostas pela Conferência de Beijing.

Referências Bibliográficas

ANISTIA INTERNACIONAL. Comunicado à Imprensa. Disponível em:

<http://www.amnesty.org/en/library/asset/ACT77/034/2004/en/8d622b78d60e-11dd-bb24-1fb85fe8fa05/act770342004pt.pdf>. Acesso em: 21/06/2011.

ALVEZ, José Augusto Lindgren. Relações Internacionais e Temas Sociais: a década das conferências. Brasília: IBRI, 2001.

BOURDIEU, Pierre. A Dominação Masculina. São Paulo: Ática, 1999.

DI SABBATO, Alberto (org.) et alii. Estatísticas Rurais e a Economia Feminista: um olhar sobre o trabalho das mulheres. Brasília: Ministério do Desenvolvimento Agrário, 2009.

GUTERRES, Simone Bastos. Classe social e gênero: elementos para uma controvérsia. Campinas: Dissertação de Mestrado em Sociologia apresentada à Unicamp, 2001. 


\section{Artigo original}

Hegemonia - Revista Eletrônica de Relações Internacionais do Centro Universitário Unieuro

ISSN: $1809-1261$

UNIEURO, Brasília, número 11, 2013, pp. 166-199

MARTINS, Estevão Chaves de Rezende. Relações Internacionais: cultura e poder. Brasília: IBRI, 2002

NAÇÕES UNIDAS, Organização das. Declaración y Platafroma de Acción de Beijing com La Declaración Política y el Documento Final "Beijing + 5". Beijing: Organização das Nações Unidas, 1995.

. O Progresso das Mulheres no Brasil. Disponível em:

<http://www.generoracaetnia.org.br/publicacoes/Progresso\%20das\%20Mulher es-BR.pdf>. Acesso em: 21/06/2011.

NOGUEIRA, João Pontes e MESSARI, Nizar. Teoria das Relações Internacionais. São Paulo: Campos, 1995.

REPÚBLICA DO BRASIL, Presidência da. Lei número 10.683 de 28 de Maio de 2003. Disponível em: <https://www.planalto.gov.br/ccivil_03/LEIS/2003/L10.683.htm>. Acesso em: 21 de Junho de 2011.

. Lei número 11.340 de 07 de Agosto de 2006.. Disponível em: <http://www.planalto.gov.br/ccivil_03/_ato2004-2006/2006/lei//11340.htm>. Acesso em: 20 de Junho de 2011.

- Relatório Final de Implementação: I Plano Nacional de Políticas para as mulheres - 2005 - 2007. Brasília: Secretaria de Políticas para as Mulheres, 2009.

ROCHA, Antônio Jorge da. Relações Internacionais: teorias e agendas. Brasília: IBRI, 2002.

SCOTT, Parry (org.) et alli. Gênero e Geração em Contextos Rurais. Ilha de Santa Catarina: Mulheres, 2010.

ZALEWSKI, Marysia. Well, what is the feminist perspective on Bosnia in Theories of International Relations. Estados Unidos: Hardcover, 1995. 